\title{
Design Optimization of Passenger Car Front Bumper
}

\author{
Manideep Kumar Vandanapu ${ }^{1}$, Ratnakar Pandu ${ }^{2}$ \\ ${ }^{1}$ PG Scholar (Cad/Cam), MLRITM Dundigal, Hyderabad, Telangana, India \\ ${ }^{2}$ Associate Professor, MLRITM Dundigal, Hyderabad, Telangana, India
}

\begin{abstract}
Increasing demand to the comfortable cars in low cost make the car makers try to reduce cost for potential components in a car. The dynamic crash sequence of vehicle is progressive in nature. The initial contactor (Bumper or Side Beam) deforms first, then the next structural component and the following component until the energy is absorbed. The initial contactors must be designed to withstand the anticipated crush loads for the various defined impact speeds from defined impact directions. The Insurance companies will evaluate the vehicle performance on frontal crash into a full width fixed barrier as most of the accidents occur due to frontal crash. The main purpose of bumper is to absorb shock in case of a collision. Several materials have been used to develop these shock-absorbing capabilities, such as steel, aluminum, glass mat thermoplastics and sheet molding compound. The purpose of this paper is to design a bumper which is to improve crashworthiness of the bumper beam. Crashworthiness is the ability of the bumper beam to prevent occupant injuries in the event of an accident and this is achieved by minimizing the impact force during the collision. This study was investigated the difference of producing bumper beam using roll forming method compare to stamping method. Based on observations design improvements will be made in terms of shape, size and or material based on design modification objectives. The study was focused on existing design performance, advantage and limitations. Modified front bumper design will be tested using FEM software for impact loads as per international standards.
\end{abstract}

Keywords: Automotive bumper beam, Catia, CAE model, Hypermesh, LS-Dyna

\section{Introduction}

Car accidents are happening every day. Most drivers are convinced that they can avoid such troublesome situations. Nevertheless, we must take into account the statistics - ten thousand dead and hundreds of thousands to million wounded each year. These numbers call for the necessity to improve the safety of automobiles during accidents. Automotive bumper system is one of the key systems in passenger cars. Bumper systems are designed to prevent or reduce physical damage to the front or rear ends of passenger motor vehicles in collision condition. They protect the hood, trunk, grill, fuel, exhaust and cooling system as well as safety related equipment such as parking lights, headlamps and taillights, etc. A good design of car bumper must provide safety for passengers and should have low weight. Different countries have different performance standards for bumpers. Under the International safety regulations originally developed in North America, a car's safety systems must still function normally after a straight-on pendulum or movingbarrier impact of $4.4 \mathrm{~km} / \mathrm{h}$ to the front and to the front corners of $2.8 \mathrm{~km} / \mathrm{h}$ at 20 " above the ground with the vehicle loaded or unloaded. In North America (FMSS: Federal Motor Vehicle Safety Standards)

Today, it is common to produce structural body parts via stamping or hydroforming. The structural and complexity potential of stamped and hydroformed steel parts is very high however, machine investment costs for these manufacturing processes are significant. In addition, the tools can be complicated and costly. A process offering an economic alternative to the above mentioned is roll forming.

In conventional bumper beam, to produce this bumper beam is using stamping process but it cost a lots of money due to in stamping process it involve a lots of process likes drawing, trimming, piercing and flanging. If many process involve the probability to make mistake is higher. It will make the cost of the bumper become higher when there a lots of mistake in each process.

\section{Literature Survey}

Javad Marzbanrad. et al., Design and analysis of an automotive bumper beam in low-speed frontal crashes, studied the most important parameters including material, thickness, shape and impact condition for design and analysis of an automotive front bumper beam to improve the crashworthiness design in low-velocity impact. The simulation of original bumper under condition impact is according to the low-speed standard of automotives stated in FMVSS and IIHS. The bumper beam analysis is accomplished for Stamping and Roll form to compare the weight and impact behavior. The strength in elastic mode is investigated with energy absorption and impact force in maximum deflection situation. A good design of this part of automotives must prepare for the safety of passengers; meanwhile, should have low weight.

Andersson $\mathrm{R}$ et.al emphasized that to increase crash performance in automotive vehicles it is necessary to use new techniques and materials. The components that are linked to crash safety should transmit or absorb energy. The energy absorbing capability of a specific component is a combination of geometry and material properties. The chosen material should have high yield strength and relatively high elongation to fracture. These demands lead to increase interest to use of high strength stainless steels.

Willem Witteman et al, Adaptive frontal structure design to achieve optimal deceleration pulses, discuss possibilities to design an adaptive vehicle structure that can change the 


\section{International Journal of Science and Research (IJSR) \\ ISSN (Online): 2319-7064 \\ Index Copernicus Value (2013): 6.14 | Impact Factor (2014): 5.611}

stiffness real time for optimal energy absorption in different crash situations. Besides that all the energy which is absorbed is also important to manage the intensity during the crash time, because the resulting crash pulse has a large influence on the injury level due to predetermined crash velocity. This implies that in a given vehicle concept the structure must have a specific stiffness. Normally, the two main frontal rails have to absorb most of the crash energy with a progressive folding deformation of a steel column.

In this paper, O. G. Lademo et.aldiscusses about a Roll form bumper beam is presented for potential application in vehicle bumper. Through numerical simulation of the bending behavior under impact loads, the Roll form bumper beam is compared with Stamping beam in crashworthiness. The effects of the shape of the Roll form beam and the shape optimization design is performed for increasing energy absorption and reducing the initial peak force. The bumper system is a structural component, which contributes to the crashworthiness or occupant's protection during a front or rear collision. There is an interest among the researchers to move from Stamping to Roll form beam. Minaudo et al. (1997) developed a Roll form bumper system with impact protection. Clark et al. (1991) described their extensive work on bumper beams using Bumper standards over the last few years.

This bumper absorbs impact energy with its deformation or transfers it perpendicular to the impact direction with the aid of a spring mechanism that is able to convert about $80 \%$ of the kinetic energy to the spring potential energy in low speed impacts according to American standard. The main design concepts of this bumper are based on aerodynamic forms and frontal configuration of passenger cars. The CATIA data of the bumper structure have imported to LS-Dyna and analyses have done with nonlinear explicit impact modeling elements. Modeling, solving and analysis were carried out with respect to the American standard and a bumper assembly was designed with $9.8 \mathrm{~kg}$ weight which has reduced compared with a similar stamping steel bumper.

\section{Bumper Systems}

There are several factors that an engineer must consider when selecting a bumper system. The most important factor is the ability of the bumper system to absorb enough energy to meet the OEMs internal bumper standard. Weight, manufacturability and cost are also important factors that engineers consider during the design phase. The formability of materials is important for high-sweep bumper systems. Another factor considered is recyclability of materials, which is a definite advantage for steel. As shown in Figure 1, there are five bumper systems in common use today:

1) Metal face bar

2) Plastic fascia and reinforcing beam

3) Plastic fascia, reinforcing beam and mechanical energy absorbers

4) Plastic fascia, reinforcing beam and foam or honeycomb energy absorber

5) Plastic fascia, reinforcing beam, foam, and mechanical energy absorbers

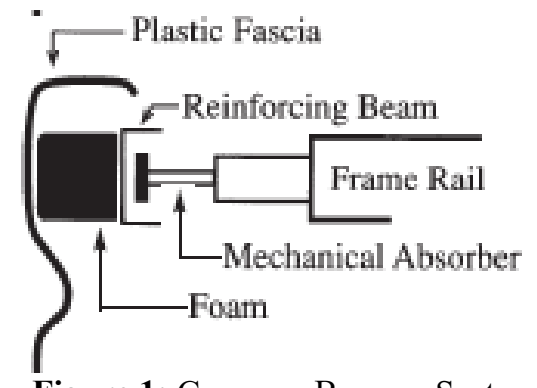

Figure 1: Common Bumper Systems

\subsection{Reinforcing beam}

The reinforcing beams (Figure 2) are key components of the bumper systems that employ them. Reinforcement beams help absorb the kinetic energy from a collision and provide protection to the rest of the vehicle. By staying intact during a collision, beams preserve the frame. Design considerations for reinforcing beams include strength, manufacturability, weight, recyclability and cost. Steel reinforcing beams are usually roll formed or hot stamped using ultra high-strength steel. Typical cross sections are shown in Figure 2.2. Roll formed beams are the most common but hot stamped beams have the lowest average mass of all steel bumper systems and are becoming more popular as a result. The most common cross section for roll formed beams is the B-section and the most common sections for hot stamped beams are box and hat sections. Sometimes a stamped or roll formed face or back plate is welded to a roll formed or hot stamped $\mathrm{C}$-section to create a boxed section. Additional reinforcements are sometimes welded to reinforcing beams, such as pole protectors and bulkheads. All steel reinforcing beams receive corrosion protection. Some beams are made from hot-dip galvanized or electro galvanized sheet. The zinc coating on these products provides excellent corrosion protection. Other beams are protected after fabrication with a paint system such as E-coat. Since steel reinforcing beams are becoming stronger and lighter with thinner gauges being used, more beams are using both zinc coating and E-coating to meet corrosion protection requirements.
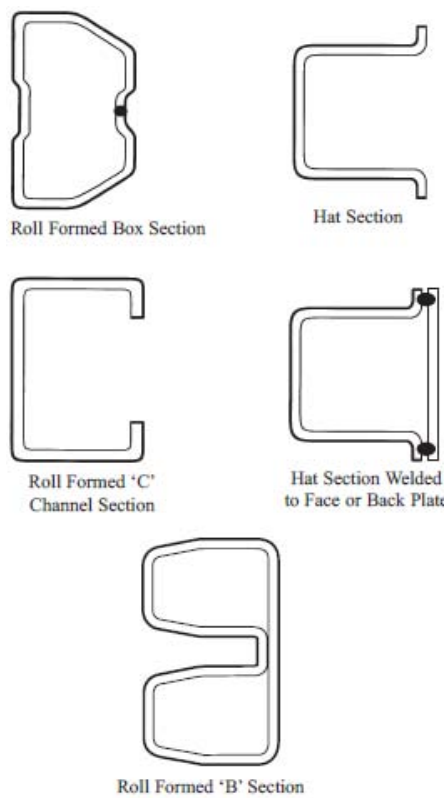

Figure 2: Common Reinforcing beam cross sections 


\section{International Journal of Science and Research (IJSR) \\ ISSN (Online): 2319-7064}

Index Copernicus Value (2013): 6.14 | Impact Factor (2014): 5.611

\section{Relevant Safety Standards in North America and Europe}

The bumper standard prescribes performance requirements for passenger cars in low-speed front collisions. It applies to front and rear bumpers on passenger cars to prevent the damage to the car body and safety related equipment at different barrier impact speeds of across the full width and on the corners. The standard requires protection in the region 16 to 20 inches above the road surface and the manufacturer can provide the protection by any means it wants. For example, some vehicles do not have a solid bumper across the vehicle, but meet the standard by strategically placed bumper guards and corner guards.

The Insurance Institute for Highway Safety (IIHS) and Federal Motor Vehicle Safety Standards (FMVSS), in an effort to reduce the cost of passenger vehicle bumper repairs, has developed a test protocol that stimulates a broader range of impacts occurring in actual on-the-road crashes. The IIHS tests, conducted on passenger cars and minivans, are more severe that the NHTSA tests. The IIHS protocol is not a pass or fails protocol. Rather, it provides a weighted damage estimate that is used to determine the overall rating for a passenger vehicle. Many OEMs select a target overall rating.

\section{The four steps defined in the standard:}

The Bumper Standard only applies to passenger cars.

A passenger vehicle is subjected to three impact procedures:

1) The flat barrier impacts into a bumper - front

2) The bumper impacts into a flat barrier - front

3) The pendulum corner impacts - front

4) The pendulum longitudinal impacts - front.

\subsection{Flat barrier impacts into a fixed bumper}

1) See figure 3

2) Flat barrier Impact speed of $16.1 \mathrm{mph}(26 \mathrm{~km} / \mathrm{h})$.

3) Impact into a fixed collision barrier perpendicular to line of travel while travelling longitudinally forward.

4) Reaction force on the barrier is measured w.r.t to stroke of the barrier.

\section{Requirements}

1. Force vs. Stroke curve should be between the given boundaries defined in the standard.

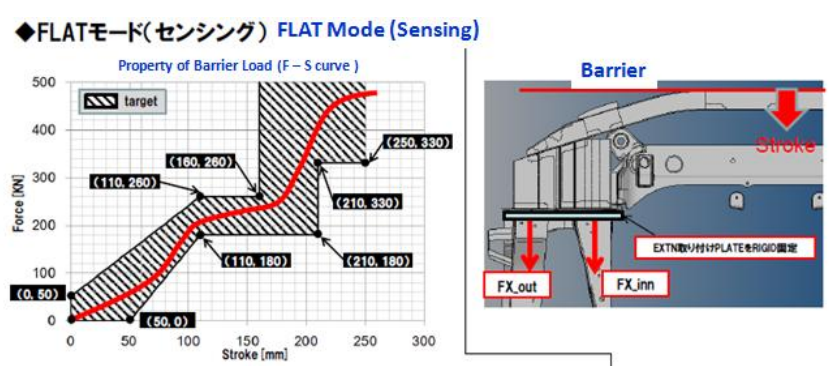

Figure 3: Flat barrier impacts into a fixed bumper

\subsection{Bumper impacts into a fixed flat barrier}

1) See figure 4

2) Bumper Impact speed of $2.73 \mathrm{mph}(4.4 \mathrm{~km} / \mathrm{h})$.
3) Impact into a fixed collision barrier perpendicular to line of travel while travelling longitudinally forward.

4) Reaction force on the barrier is measured w.r.t to stroke of the barrier.

Requirements:

1) Position of back side of beam (OB) to be stopped at before $\mathrm{X}$ direction of $-693 \mathrm{~mm}$.

2) Peak load (one side) of FX1 should be less than $90 \mathrm{kN}$ and FX2 should be less than $40 \mathrm{kN}$ as shown in the above image.

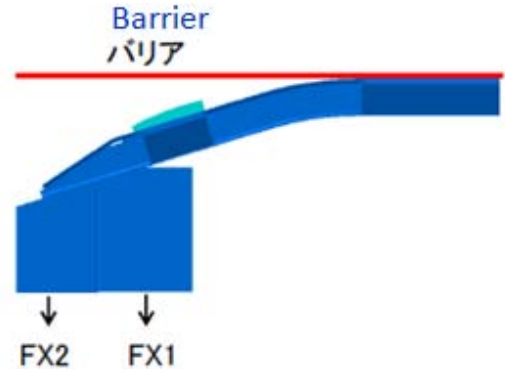

Figure 4: Bumper impacts into a fixed flat barrier

\subsection{Pendulum Corner Impacts}

1) See figure 5 .

2) Pendulum Impact speed of $1.7 \mathrm{mph}(2.8 \mathrm{~km} / \mathrm{h})$.

3) Impact front corner at a height of 20 inches $(508 \mathrm{~mm})$

4) The plane containing the pendulum swing shall have a 60 degree angle with the longitudinal plane of the vehicle.

5) Impacts must be performed at intervals not less than 30 minutes.

6) Effective impacting mass of pendulum equals mass of vehicle.

\section{Requirements:}

1) Stroke of the Pendulum from the first position at corner 20 inch should be less than $44 \mathrm{~mm}$

2) Position of back side of beam to be stopped at before at $T$ $=-698 \mathrm{~mm}$

3) Peak load (one side) of FX1 should be less than $90 \mathrm{kN}$ and FX2 should be less than $40 \mathrm{kN}$.

4) Absorbed energy of the Bumper assembly should be 176 $\mathrm{J}(85 \%)$

\subsection{Pendulum longitudinal (Center) impacts}

1) See figure 5

2) Impact speed of $2.73 \mathrm{mph}(4.4 \mathrm{~km} / \mathrm{h})$.

3) Impacts on front surface, inboard of corner.

4) Impact line should be the height from 20 inches (508 $\mathrm{mm})$.

5) Pendulum Plane A is perpendicular to the longitudinal plane of the vehicle.

6) Impacts must be performed at intervals not less than 30 minutes apart.

7) Effective impacting mass of pendulum equals mass of Vehicle.

\section{Requirements:}

1) Stroke of the Pendulum from the first position at Center OB 20 inch should be less than $53 \mathrm{~mm}$. 


\section{International Journal of Science and Research (IJSR) \\ ISSN (Online): 2319-7064 \\ Index Copernicus Value (2013): 6.14 | Impact Factor (2014): 5.611}

2) Position of back side of beam to be stopped at before $\mathrm{T}=$ $-698 \mathrm{~mm}$.

3) Peak load (one side) of FX1 should be less than $90 \mathrm{kN}$ and FX2 should be less than $40 \mathrm{kN}$.

4) Absorbed energy of the Bumper assembly should be 434 $\mathrm{J}(85 \%)$.

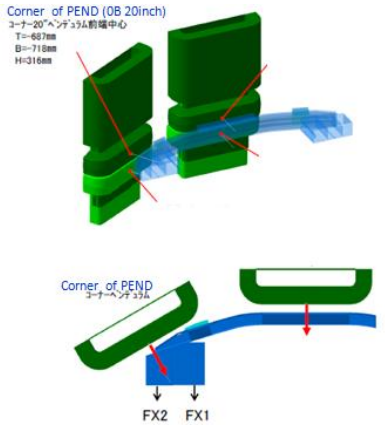

Figure 5: Pendulum Corner and Center Impacts

\subsection{Insurance Institute for Highway Safety}

\section{a. Full Overlap Impact}

1) See figure 6

2) The front bumper impacts into a flat barrier

3) Impact speed of $10.8 \mathrm{~km} / \mathrm{h}$.

4) The forwarding portion of the bottom edge of the bumper barrier is $323 \mathrm{~mm}$ from the floor.

\section{Requirements}

1) Position of the beam (OB) to be stopped at before at $T=-$ $698 \mathrm{~mm}$

2) Peak load (one side) of FX1 should be less than $90 \mathrm{kN}$ and FX2 should be less than $40 \mathrm{kN}$.

3) Position of lowermost of beam to be stopped at before the height of $\mathrm{H}=187 \mathrm{~mm}$.

4) Absorbed energy of the Bumper assembly should be 5200 $\mathrm{J}(90 \%)$

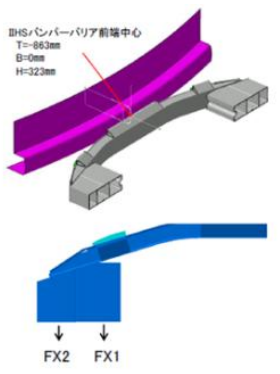

Figure 6: Full Overlap Impact

b. Corner impact

1) See figure 7

2) The front bumper impacts to the barrier at the corner. See figure below

3) Impact speed of $5.3 \mathrm{~km} / \mathrm{h}$.

4) The forward most portion of the bottom edge of the bumper barrier is $259 \mathrm{~mm}$ from the floor.

5) Absorbed energy of the Bumper assembly should be 974 $\mathrm{J}(70 \%)$

\section{Requirements}

1) Stroke of barrier from the first position should be less than $154 \mathrm{~mm}$.
2) Peak load (one side) of FX1 should be less than $90 \mathrm{kN}$ and FX2 should be less than $40 \mathrm{kN}$.

3) Absorbed energy of the Bumper assembly should be 974 $\mathrm{J}(70 \%)$.

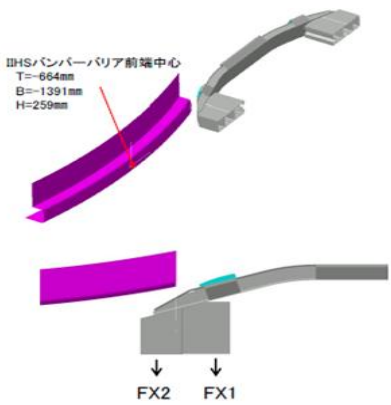

Figure 7: Corner impact

\section{Modeling}

Table 1: Design data collection

\begin{tabular}{|c|c|}
\hline \multicolumn{2}{|c|}{ Dimension Unit (mm) } \\
\hline Circle of radius (R1) & 1100.08 \\
\hline Circle of radius (R2) & 755.97 \\
\hline Chord length (L) & 1501 \\
\hline Depth of draw (X) & 189 \\
\hline Width & 46 \\
\hline Thickness & 1 \\
\hline Profile & Box section \\
\hline
\end{tabular}

Various Proposals of Bumper beam:

The following geometry model Figure 8,9,10 of automobile bumper has been made by using Catia V5 software.

Baseline model consists of all stamped parts, whereas Proposal 1 has all roll formed parts. Proposal 2 is combination of Roll formed beam and stamped crush tips.

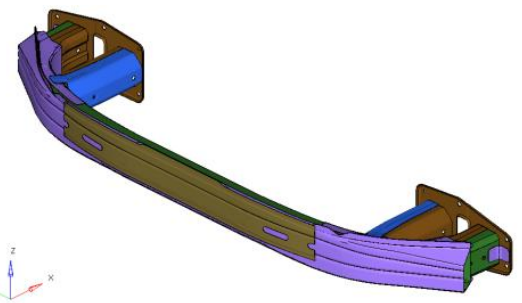

Figure 8: Baseline - Stamping Bumper Beam Proposal

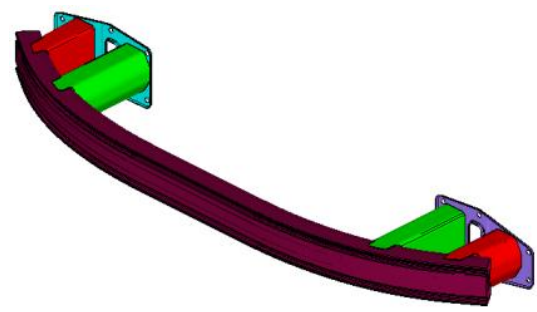

Figure 9: Proposal 1 - Roll form Bumper Beam Proposal 


\section{International Journal of Science and Research (IJSR) \\ ISSN (Online): 2319-7064}

Index Copernicus Value (2013): 6.14 | Impact Factor (2014): 5.611

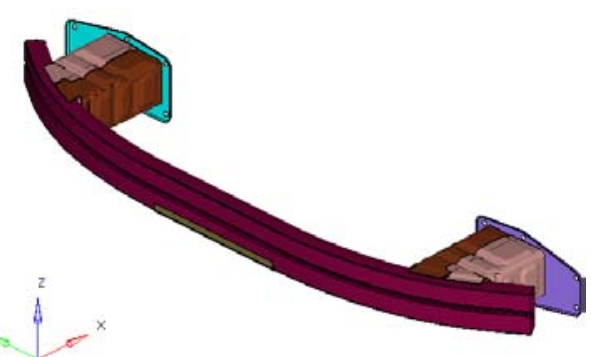

Figure 10: Proposal 2 - Roll form Bumper Beam and stamped crush tips Proposal

\begin{tabular}{|c|c|c|c|c|}
\hline Sl. No. & Par Name & $\begin{array}{l}\text { Thickness } \\
(\mathrm{mm})\end{array}$ & $\begin{array}{l}\text { Weight } \\
(\mathrm{Kg})\end{array}$ & Process \\
\hline 1 & Beam & 1 & 3.542 & Roll Formed \\
\hline 2 & REINF_BEAM & 1 & 0.2919 & Stamping \\
\hline 3 & CRASH_BOX_OT & 2.3 & 0.9898 & Stamping \\
\hline 4 & CRASH_BDX_INR & 2.7 & 1.4666 & Stamping \\
\hline 5 & BACK_PLATE & 1.5 & 0.5672 & Stamping \\
\hline & \multicolumn{2}{|c|}{ TotalMass (Kg) } & 9.881 & \\
\hline
\end{tabular}

Proposal 2 - Geometry Parameters

\section{Material Used}

These Bumper beam and crush cans assemblies are made of cold rolled high-strength Automotive Sheet Steel, SAE J2340.

Chemical composition:
Copper
$0.200 \%$
Sulphur
$0.015 \%$
Molybdenum
$0.06 \%$
Nickel
$0.200 \%$
Phosphorus
$0.020 \%$
Chromium
$0.150 \%$

\section{Mechanical Properties:}

Yield Strength (0.2\% Offset) - 950Mpa

Tensile Strength - 1200Mpa

Modulus of Elasticity E - 2.1e5Mpa

Poisson's Ratio $(v)-0.3$

Density $(\rho)-7.89$ e $-6 \mathrm{Kg} /$ cubic mm.

\section{Analysis Of Car Bumper With FEA Software LS Dyna (Results)}

Proposal 2 - Meshed model using Hyper mesh:

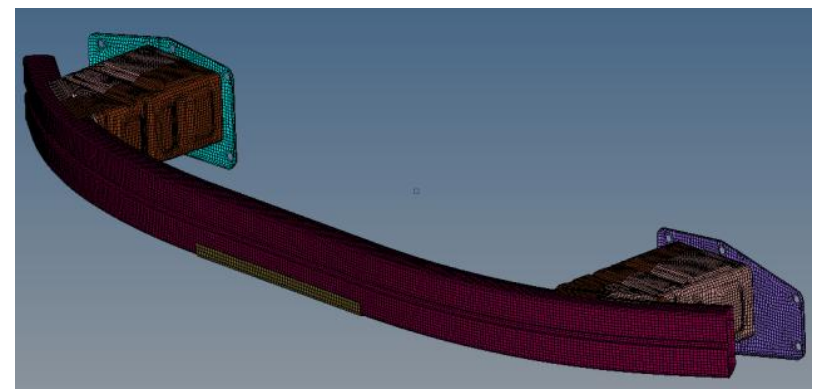

5.1 The flat barrier impacts into a bumper - front

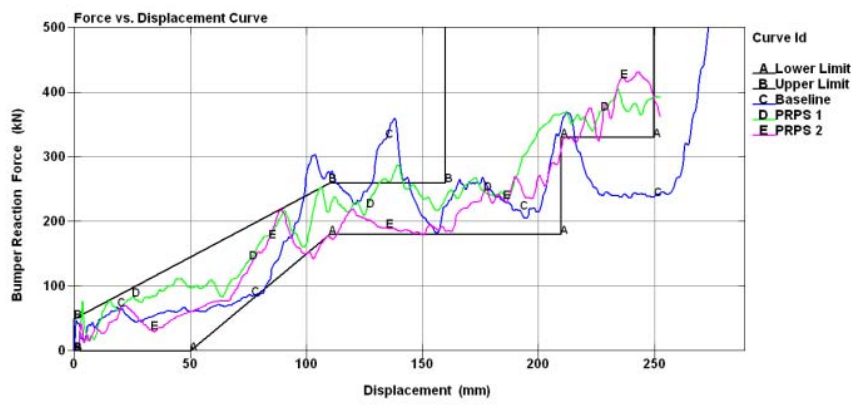

Graph 1: Results FMVSS 26kmph -Force vs. Displacement

Observations: The Proposal 2 model was found to meet the FMVSS target for $26 \mathrm{kmph}$ requirement.

5.2 The bumper impacts into a flat barrier - front:

Table 2: Results - FMVSS 4.4kmph Flat barrier

\begin{tabular}{|c|c|c|c|c|}
\hline \multicolumn{2}{|c|}{ Targets } & Baseline & Proposal 1 & Proposa12 \\
\hline Peak load(one side) & Fx1 <90kN & 23.70 & 41.90 & \multirow{2}{*}{27.20} \\
\cline { 2 - 4 } & Fx2 $440 \mathrm{kN}$ & 13.40 & 8.20 & \\
\hline $\begin{array}{c}\text { Position of backside of } \\
\text { the beam to be stopped } \\
\text { before T= 698mm }\end{array}$ & $\mathrm{T}=698 \mathrm{~mm}$ & 768.00 & 774.00 & 782.00 \\
\hline Absorbed energy & $1020 \mathrm{~J}(100 \%)$ & 1039 & 976 & 983 \\
\hline
\end{tabular}

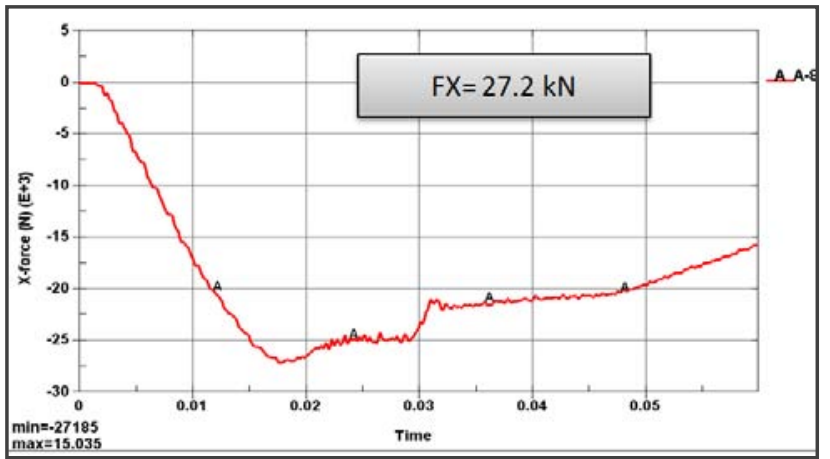

Graph 2: FMVSS 4.4kmph -Force vs. Time

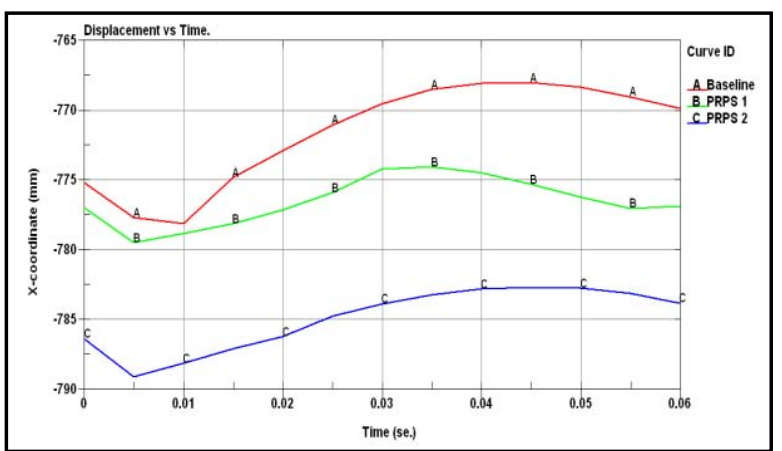

Graph 3: FMVSS 4.4kmph -Displacement vs. Time

Observations: The Proposal 2 model was found to meet the FMVSS target for $4.4 \mathrm{kmph}$ requirement. 


\section{International Journal of Science and Research (IJSR) \\ ISSN (Online): 2319-7064}

Index Copernicus Value (2013): 6.14 | Impact Factor (2014): 5.611

\subsection{Pendulum Corner Impacts:}

Table 3: Results - FMVSS 2.8 kmph 20" Pendulum corner

\begin{tabular}{|c|c|c|c|c|}
\hline \multicolumn{2}{|c|}{ Targets } & Baseline & Proposal 1 & Proposa1 2 \\
\hline Peak load(one side) & Fx1 $<90 \mathrm{kN}$ & $-21.45 \mathrm{kN}$ & $24.4 \mathrm{kN}$ & \multirow{2}{*}{$27.3 \mathrm{kN}$} \\
\cline { 2 - 4 } & Fx2 $400 \mathrm{kN}$ & $-14.26 \mathrm{kN}$ & $30.0 \mathrm{kN}$ & \\
\hline $\begin{array}{c}\text { Position of backside of } \\
\text { the beam to be stopped } \\
\text { before T= 698mm }\end{array}$ & $\mathrm{T}=698 \mathrm{~mm}$ & 775.10 & 775.60 & 784.80 \\
\hline Absorbed energy & $176 \mathrm{~J}(80 \%)$ & 455 & 353 & 249 \\
\hline Stroke of PEND & $<44 \mathrm{~mm}$ & 18.46 & 10.00 & 13.7 \\
\hline
\end{tabular}

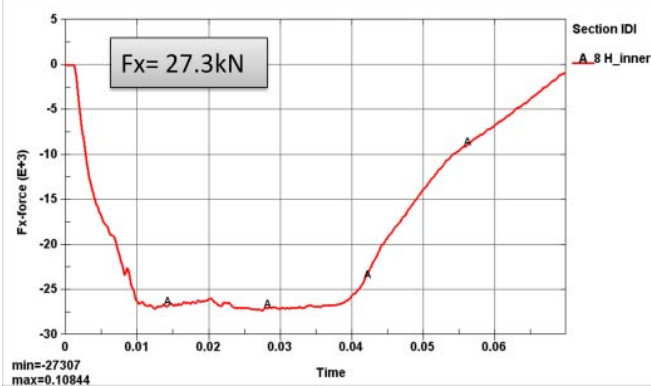

Graph 4: FMVSS 2.8kmph -Force vs. Time

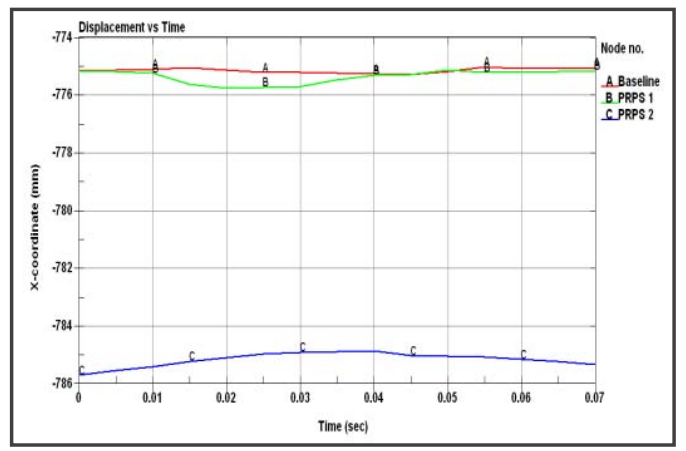

Graph 5: FMVSS 2.8kmph -Displacement vs. Time

Observations: The Proposal 2 model was found to meet the FMVSS target for $2.8 \mathrm{kmph}$ requirement.

\subsection{Pendulum longitudinal (center) impacts:}

Table 4: Results - FMVSS 4.4 kmph 20" Pendulum center

\begin{tabular}{|c|c|c|c|c|}
\hline \multicolumn{2}{|c|}{ Targets } & Baseline & Proposal 1 & Proposa1 2 \\
\hline Peak load(one side) & Fx1 <90kN & $19.22 \mathrm{kN}$ & 30.47 & \multirow{2}{*}{16.00} \\
\cline { 2 - 4 } & Fx2 $440 \mathrm{kN}$ & $9.01 \mathrm{kN}$ & 4.99 & \\
\hline $\begin{array}{c}\text { Position of backside of } \\
\text { the beam to be stopped } \\
\text { before T= 698mm }\end{array}$ & $\mathrm{T}=698 \mathrm{~mm}$ & 739.82 & 742.50 & 745.80 \\
\hline Absorbed energy & $434 \mathrm{~J}(80 \%)$ & 1076 & 968 & 980 \\
\hline Stroke of PEND & $<53 \mathrm{~mm}$ & 36.80 & 30.80 & 44.96 \\
\hline
\end{tabular}

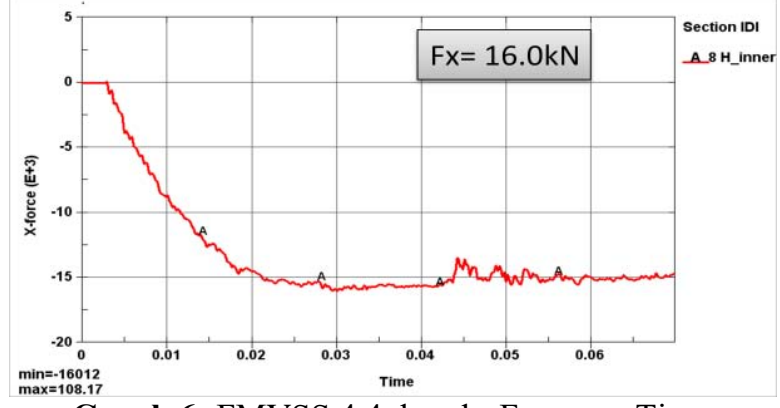

Graph 6: FMVSS 4.4 kmph -Force vs. Time

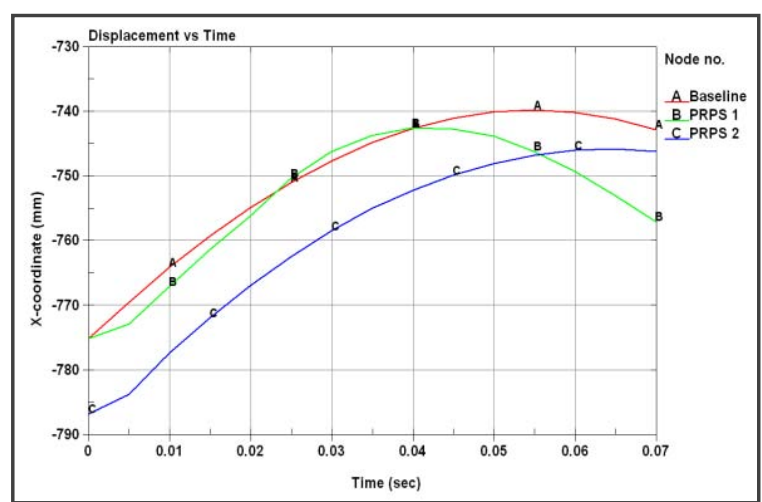

Graph 7: FMVSS 4.4 kmph -Displacement vs. Time

Observations: The Proposal 2 model was found to meet the FMVSS target for $4.4 \mathrm{kmph}$ requirement.

\subsection{Insurance Institute for Highway Safety:}

\section{a. Full Overlap Impact}

Table 5: Results - IIHS $10.8 \mathrm{kmph}$

\begin{tabular}{|c|c|c|c|c|}
\hline \multicolumn{2}{|c|}{ Targets } & Baseline & Proposal 1 & Proposa12 \\
\hline Peak load(one side) & Fx1 $400 \mathrm{kN}$ & $36.9 \mathrm{kN}$ & $49.58 \mathrm{kN}$ & \multirow{2}{*}{$33.97 \mathrm{KN}$} \\
\cline { 2 - 4 } & Fr2 $440 \mathrm{kN}$ & $11.5 \mathrm{kN}$ & $22.5 \mathrm{kN}$ & \\
\hline $\begin{array}{c}\text { Position of backside of } \\
\text { the beam to be stopped } \\
\text { before T=698mm }\end{array}$ & $\mathrm{T}=698$ & 775.60 & 802.00 & 852.42 \\
\hline $\begin{array}{c}\text { Position of the lower most } \\
\text { beam to be stopped } \\
\text { before H=187mm }\end{array}$ & $\mathrm{H}=187$ & 203.90 & 162.00 & 199.47 \\
\hline Absorbed energy & $5200 \mathrm{~J}(90 \%)$ & 5790 & 3434 & 5516 \\
\hline
\end{tabular}

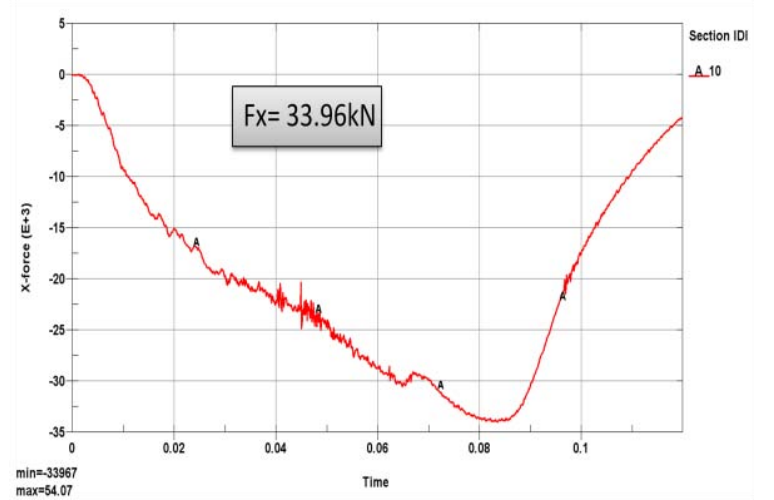

Graph 8: IIHS 10.8kmph -Force vs. Time

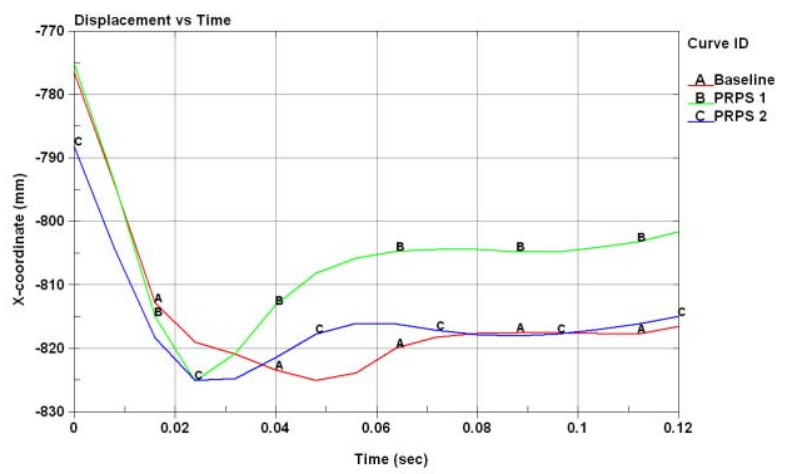

Graph 9: IIHS 10.8kmph -Displacement vs. Time 


\section{International Journal of Science and Research (IJSR) \\ ISSN (Online): 2319-7064}

Index Copernicus Value (2013): 6.14 | Impact Factor (2014): 5.611

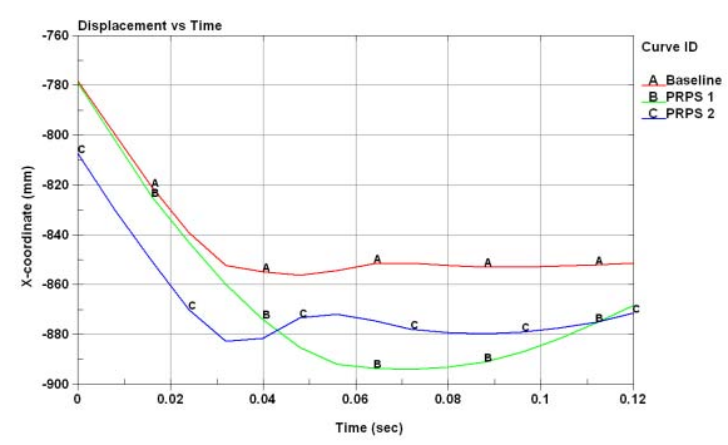

Graph 10: IIHS 10.8kmph -Displacement vs. Time

Observations: The Proposal 2 model was found to meet the IIHS target for $10.8 \mathrm{kmph}$ requirement.

\section{b. Corner impact}

Table 5: Results - IIHS corner $5.3 \mathrm{kmph}$

\begin{tabular}{|c|c|c|c|c|}
\hline \multicolumn{2}{|c|}{ Targets } & Baseline & Proposal 1 & Proposa12 \\
\hline \multirow{2}{*}{ Peak load(one side) } & Fx1 <90kN & $16.15 \mathrm{KN}$ & $24.1 \mathrm{kN}$ & \multirow{2}{*}{$39.23 \mathrm{kN}$} \\
\cline { 2 - 4 } & Fx2<40 $\mathrm{kN}$ & $35.4 \mathrm{KN}$ & $48.9 \mathrm{KN}$ & \\
\hline $\begin{array}{c}\text { Stroke of barrier (from } \\
\text { first position) }\end{array}$ & $<154 \mathrm{mmm}$ & 108.70 & 81.40 & 129.53 \\
\hline Aborbed energy & $974 \mathrm{~J}(70 \%)$ & 1248 & 1127 & 1250 \\
\hline
\end{tabular}

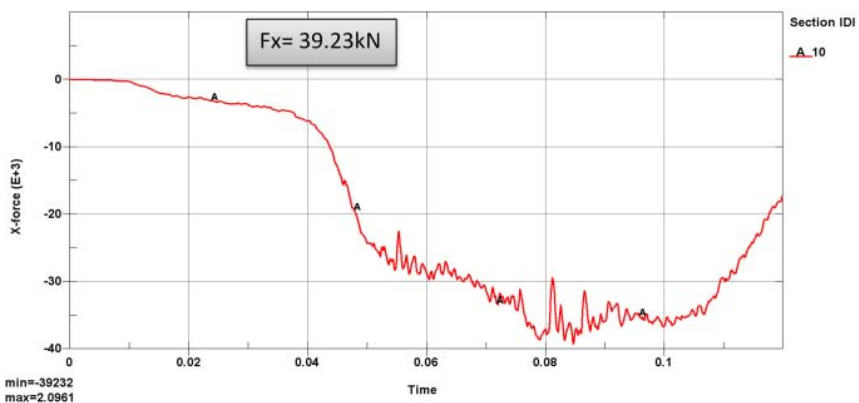

Graph 11: IIHS $5.3 \mathrm{kmph}$-Force vs. Time

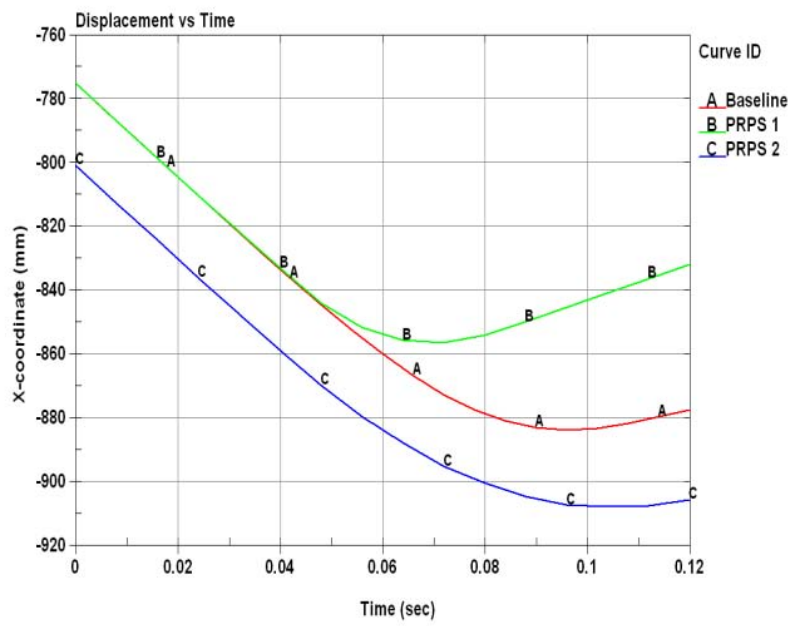

Graph 12: IIHS 5.3kmph -Displacement vs. Time

Observations: The Proposal 2 model was found to meet the IIHS target for $5.3 \mathrm{kmph}$ requirement.

\section{Conclusions}

From the above work, it can be concluded that the bumper is an important member of an automobile from the safety point of view. Thus the analysis of bumper will help to increase the safety of the passengers and new size and shape can also be considered to replace the existing one.

\section{References}

[1] North American Bumper System Market study,2008/2009 and 2012 estimates, Ducker Worldwide, 1250 Maplelawn Drive, Troy, MI48084.

[2] Hosseinzadeh RM, Shokrieh M, and Lessard LB, "Parametric study od automotive composite bumper beams subjected to low-velocity impacts", J. Composite Stuct., 68 (2005):419-427.

[3] http://www.google.com/patents/about/6817638_Bumper system.html?id=c1gQAAAAEBAJ.

[4] Butler M, Wycech J, Parfitt J, and Tan E, "Using Terocore Brand Structural Foam to Improve Bumper Beam Design", SAE Technical Paper, 2002.

[5] Witteman WJ, "Improved Vehicle Crashworthiness Design by Control of the Energy Absorption for Different Collision Situations", Doctoral dissertation, Eindhoven University of Technology, 2000. 